\title{
Assessing oil spill risk in the Chinese Bohai Sea: A case study for both ship and platform related oil spills
}

\author{
Xin Liu ${ }^{a}$, Ruolin Meng ${ }^{a}$, Qianguo Xing ${ }^{a}{ }^{*}$, Mingjing Lou ${ }^{a}$, Hui Chao ${ }^{b}$, Lei Bing ${ }^{a}$ \\ ${ }^{a}$ Key Laboratory of Coastal Environmental Processes and Ecological Remediation, Yantai Institute of Coastal Zone Research, \\ Chinese Academy of Sciences, Yantai 264003, PR China \\ ${ }^{\mathrm{b}}$ Hebei United University, Tangshan 063009, PR China
}

\section{A R T I C L E I N F O}

Article history:

Available online $\mathrm{xxx}$

\begin{abstract}
A B S T R A C T
Many oil spill accidents have occurred in the Chinese Bohai Sea recently because of extensive offshore oil exploitation and maritime transportation. In this study we made an attempt towards the development of a probabilistic model assessing the oil spill risks for the Bohai Sea. We utilized satellite images together with historic accident data from 1973 to 2002 and information from literature to establish probability of oil spills, which was then adjusted for the consequence of spill impacts. The assessment represented a distribution of oil spill risk in the study area. Totally, seven high risk zones have been identified, providing useful information on the optimal locations for oil spill recovery and cleanup equipment to improve spill-response readiness in the region. We anticipated that the results would contribute to the mitigation of the harmful effects of future oil spills in the Bohai Sea, if the presented model was used with care.
\end{abstract}

๑) 2014 Elsevier Ltd. All rights reserved.

\section{Introduction}

As the oil spill of Penglai 19-3 drilling platform taking place and its devastating economic loss of aquaculture in the Chinese Bohai Sea in 2011, it raised the public's awareness of the possibility of oil spill accidents taking place and leaving this vulnerable coastal zone polluted. The Chinese Bohai sea, a C-shaped semiclosed water body with an average of water depth of $18 \mathrm{~m}$, has significant ecosystem and important economy as well. However, both extensive offshore oil drilling activities and frequent sea transportation have recently posed a serious risk to the Bohai Sea. In terms of the environmental hazard, Crichton (1999) defined the risk as the probability of a loss. There is a regulatory and contingency planning demand for oil spill risk assessment model which produces probabilistic estimates of oil spill occurrence and the corresponding extent of damages on affected places (Santos et al., 2013). Here the risk analysis involved two aspects: oil spill potential specificities and vulnerability of environmental resources. An attempt of modeling has been suggested to estimate the spill potential specificities (Vethamony et al., 2007; Lamine and Xiong, 2013; El-Fadel et al., 2012). Among them, an initial development for the oil spill risk analysis model was in 1975 by the DOI (the

\footnotetext{
* Corresponding author.

E-mail address: qgxing@yic.ac.cn (Q. Xing).
}

Department of the Interior) of the federal government of the United State of America (USA) to assess possible oil spill impact from offshore oil operations (Smith et al., 1982). This model summarized the statistical results from a number of spills' trajectory simulations, which provided a table of probability of hitting environmental resources by hypothetical oil spills. To deal with vulnerability of environmental resources, both quantitative and qualitative methods have been developed worldwide in recent years (Castanedo et al., 2009; Romero et al., 2013; Hanna, 1995; Nansingh and Jurawan, 1999). Usually, GIS (Geographic Information System) was used for visualization of vulnerability to oil spills in an intuitive way. For example, Environmental Sensitivity Index (ESI) mapping was developed by NOAA (National Oceanic and Atmospheric Administration, USA) in 1970s to provide a concise summary of coastal resources that were at risk if an oil spill occurred nearby (Gundlach and Hayes, 1978; Petersen et al., 2002). So far the oil spill risk has not been fully studied for the Chinese Bohai Sea. Most likely it is lack of data, both on observed likelihood based on historical data and pollution effects. In this study, we had a focus on both ship and oil drilling platform related oil spills in the Chinese Bohai Sea. Following Etkin (2006), we mapped spatial risk of potential oil spills which incorporated the location of spills, spill probability coupled with consequence of pollution impact. 


\section{Methods}

Satellite images were investigated to identify locations of potential spills related to both ship transportation and oil drilling activities in the study area. The probability of spill was estimated by using the previous accident data in the Chinese Bohai Sea and the oil spill risk database (DNV, 2011). The impact of each spill was determined by ranking of pollution effect in a pilot survey, in which a questionnaire was presented to selected respondents.

\subsection{Establishing the context}

The Bohai Sea is a very shallow marginal sea in China with a total area of $77000 \mathrm{~km}^{2}$ and its length of coastal line is less than $2300 \mathrm{~km}$. Its average water depth is only $18 \mathrm{~m}$ and its maximal water depth is $85 \mathrm{~m}$ at the Bohai Strait. Normally, the maximal tidal range in the Bohai Sea is lager than $4 \mathrm{~m}$ and its maximal current is around $2 \mathrm{~m} / \mathrm{s}$ (Wei et al., 2004). The Bohai Sea is characterized by tide induced currents, especially surface currents in winter are driven by a combination of the northern wind and the tide.

There have been many oil spill accidents happened in the Chinese Bohai Sea in the last years. For instance, 1500 tons of heavy oil caused by the explosion of an oil pipeline close to the Dalian harbor was spilled into the Bohai Sea in 2010 (XINHUA Press, 2010); The Penglai 19-3 spill from offshore oil drilling platform polluted $840 \mathrm{~km}^{2}$ sea water in 2011, which resulted in a catastrophic economic loss of local aquaculture (COPC, 2012); Both toxic substances of crude oil and heavy metals following an oil pipeline explosion in Qingdao were released into the sea water nearby in November 2013 (China Daily, 2013). These accidents shocked the general public and the government as well. Additionally, there is an increasing high likelihood of oil spills in the Chinese Bohai Sea due to the extensive offshore oil drilling activities and extensive maritime transportation. Therefore, assessing oil spill risk for the Chinese Bohai Sea in the context of oil spill contingency management is critically essential either to prevent oil spills prior to its happening or to combat oil spills to minimize its damage to coastal environment.

\subsection{Identifying potential sites of spills}

Locations of oil drilling platforms or ships were taken as potential sites of spills in this paper. In order to identify their locations in the investigation area, images from the USA Landsat5/TM and Landsat7/ETM + with a fine resolution of $30 \mathrm{~m}$ were used. Totally 21 images from three years: 2007, 2009 and 2010 were used to extract ships and platforms. To keep the spatial consistence, all Landsat images were first geo-referenced to the images of 2007 which were regarded as reference images. Similar to the suggestion of Wu et al. (2009), band 7 (2.08-2.35 $\mu \mathrm{m}$ ) of Landsat TM/ETM+ was used for the identification of sea surface bright target with high DN (digital number) values. Images of band $4(0.76-0.90 \mu \mathrm{m})$ were first used to mask clouds and land and cloud-free sea surface was retained for each image, then the masked images of band 7 were used with a target-searching strategy of moving window for identifying the bright pixels which have larger radiance than surrounding sea water. In this procedure, decision algorithm was used to identify whether targets of interest exist; and in case of existence, iterative threshold segmentation was applied to differentiate them (pixels in image) from the background; the coordinate of each pixel or the geometry center coordinate of each patch of pixels was extracted as the instantaneous location of ship or oil drilling platforms. For the key image-processing procedures for identify ships, please refer to the section of Supplement I in this paper; and for all the details, please refer to Meng and Xing (2013).
Based on the fact that ships are moving objects and platforms are not, targets with overlapping sites (100 m buffering radius) were regarded as oil drilling platforms, and 25 oil drilling platforms in total were identified. The image and data processing is as shown by Fig. 1. Fig. 2 shows an example of oil drilling platform in Landsat images.

\subsection{Formulating oil spill risks}

Risk is usually defined as the product of probability of spill and its impact (Etkin, 2004; French-McCay et al., 2009). For detailed categories of ship and oil platform related oil spill risk in this paper, the mathematical expression is modified as follows.

$R_{\text {ship\&oil }}=\left(P_{\text {ship }} * V_{\text {ship }} * D_{\text {ship }} * F_{\text {ship }}+P_{\text {oil }} * V_{\text {oil }} * D_{\text {oil }} * F_{\text {oil }}\right) * E$

where $R_{\text {ship\&oil }}$ refers to a comprehensive oil spill risk related to ship and platform accidents; $P_{\text {ship }}$ and $P_{\text {oil }}$ represent their likelihood of spill occurrence; $V_{\text {ship }}$ and $V_{\text {oil }}$ denote average volume of spilled oil associated with ship and platform accidents; $D_{\text {ship }}$ and $D_{\text {oil }}$ describe the density of ships and oil platform, respectively; $F_{\text {ship }}$ and $F_{\text {oil }}$ represent modifier for damage of ship and oil platform, as oil field may carry different types of oil from ship. For example, ships usually carry fuel oil and field drilling platform is characterized by crude oil; $E$ represents the effect of oil spill.

\subsection{Estimation for parameters}

We assumed that probability of ship accident $(p)$ follows a binomial distribution (Roeleven et al., 1995) and the annual probability of no ship accident in the whole Bohai Sea (i.e., $\mathrm{P}(k=0)$ ) was assumed approximately to be $5 \%$ in a conservative way. The accident probability for each individual ship in the Bohai sea is $p$, which can be derived from the following suggested equations (seen Eqs. $2-5)$ :

$P(k)=f(k, p)=\left(\begin{array}{l}n \\ k\end{array}\right) p^{k}(1-p)^{n-k}$

$P(k \geq 1)=1-P(k=0)$

$P(k=0)=\left(\begin{array}{l}n \\ 0\end{array}\right) p^{0}(1-p)^{n}$

$p=1-\sqrt[n]{0.05}$

where $n$ is the total number of ships operating in the Bohai Sea on the specific year. $n=672,1014$ and 1428 for the year 2007, 2009 and 2010, respectively. Hence, $p$ is calculated as $0.00445,0.00295$

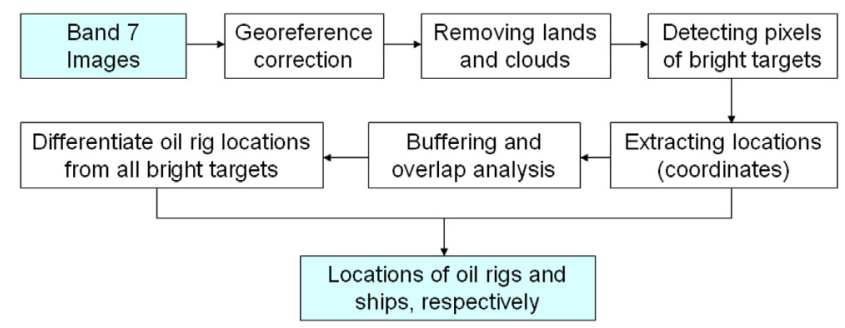

Fig. 1. The procedure of using Landsat images to determine locations of ships and oil drilling platforms, respectively. 


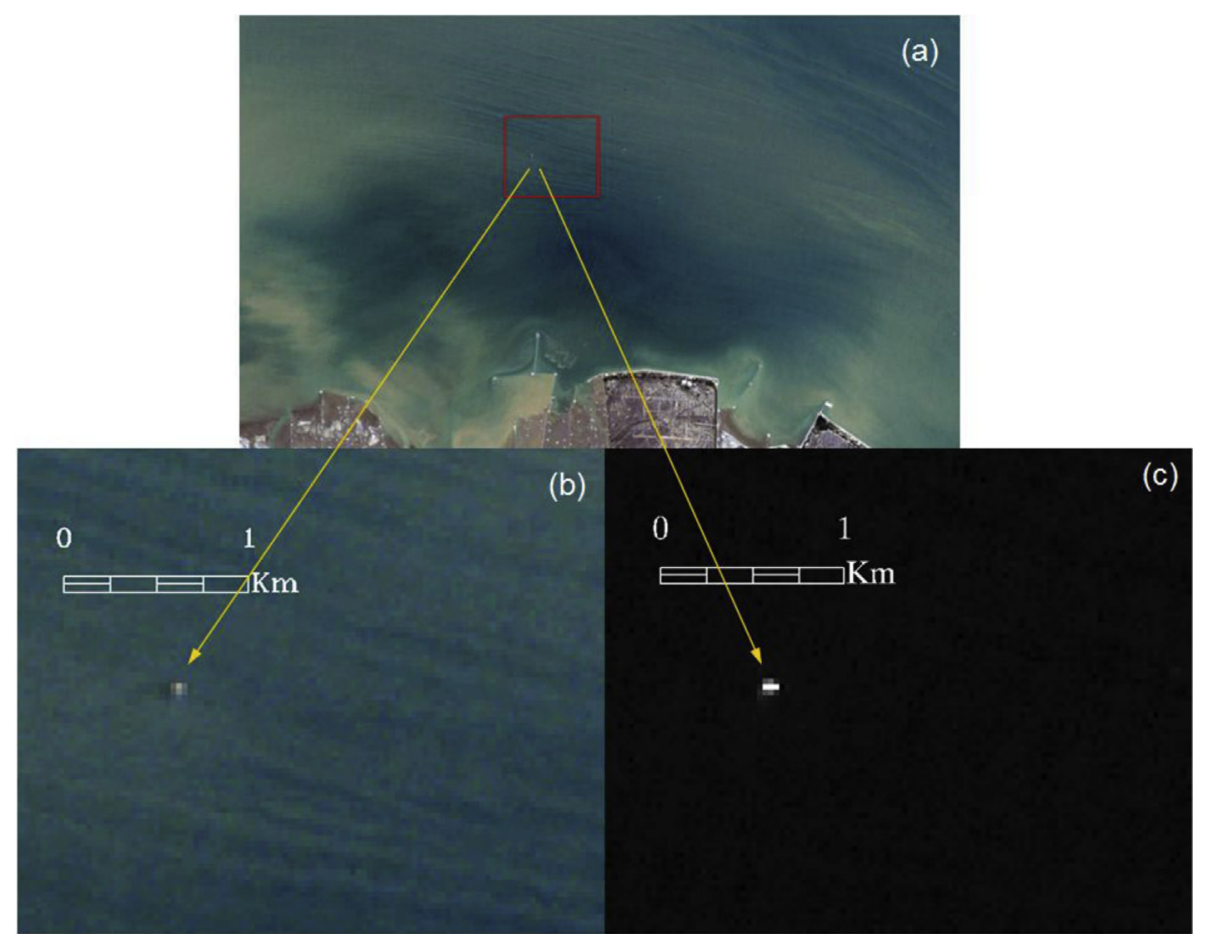

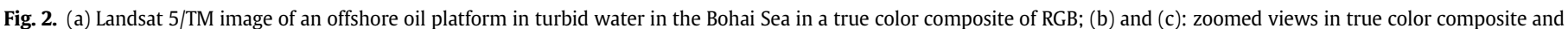
band 7 , respectively.

and 0.0021 for the corresponding year 2007, 2009 and 2010 . Apparently, the total number of ships detected has been increased significantly, if Year 2010 is compared with Year 2007. This could be attributed to fast expansion of ports in the Bohai Sea during that period. For example, ports in Liaoning province (i.e., the Northern part of the Bohai sea) has a throughput capacity less than 300 millions tons in 2005. While, their throughput capacity was increased up to 650 millions tons in 2010 according to reports by Transportation Department (Huludao Evening News, 2010). More recent details on all ports' throughputs can be seen at CHINAPORTS (http://www.chinaports.com/thruput).

$V_{\text {ship }}$ is determined by analyzing historical data of oil spills caused by ship accidents in the Bohai Sea from 1973 to 2002 (Lao, 2003), which was listed in the Table 1 . The average volume of oil

Table 1

Oil spills caused by ships in the Bohai Sea between 1973 and 2002.

\begin{tabular}{llr}
\hline Spill year & Ship type & Spill volume (tonnes) \\
\hline 1973 & Oil tanker & 1400 \\
1975 & Oil tanker & 100 \\
1976 & Oil tanker & 330 \\
1986 & Cargo ship & 200 \\
1989 & Bulk carrier & 300 \\
1990 & Bulk carrier & 100 \\
1992 & Bulk carrier & 300 \\
1992 & Container & 130 \\
1993 & Bulk carrier & 50 \\
1994 & N.A. & 100 \\
1994 & Oil tanker & 81 \\
1994 & Oil tanker & 100 \\
1995 & Bulk carrier & 460 \\
1995 & Bulk carrier & 410 \\
1996 & Bulk carrier & 150 \\
1996 & Oil tanker & 476 \\
1998 & Oil tanker & 120 \\
2002 & Oil tanker & 160 \\
\hline
\end{tabular}

Source: Lao, 2003. Only spills over 50 tons were recorded. N.A. = Not Available. spilled (i.e., $V_{\text {ship }}$ ) is 275.94 tons per spill. For consistence, $V_{\text {oil }}$ is assigned as the same value of 275.94 tons for consistency.

Following a report by Det Norske Veritas (DNV, 2011), oil spill frequency for a developing drilling platform was as high as $2.8 \times 10^{-4} V_{\text {oil }}{ }^{-0.3}$; while it was only $6.9 \times 10^{-5} V_{\text {oil }}{ }^{-0.3}$ for a developed oil platform. Totally, there were 48 oil platforms reported in domestic literature. Among the 48 oil platforms, there existed 27 developed platforms and 21 developing platforms. As mentioned above, the average volume of spill (i.e., $V_{\text {oil }}$ ) caused by oil platform was also assumed as the same as 275.94 tons. So the possibility of oil spills related to oil drilling platforms was formulated as follows:

$p_{\text {oil }}=\frac{27}{48} * 6.9 * 10^{-5} * V_{\text {oil }}^{-0.3}+\frac{21}{48} * 2.8 * 10^{-4} * V_{\text {oil }}^{-0.3}$

$D_{\text {oil }}$ and $D_{\text {ship }}$ were calculated by spatial analysis tool of "point density" using ArcToolbox in ArcGIS. Potential spill sites in images extracted by satellite data were used for calculation of density for bosh ships and drilling platforms. Each raster is $100 \mathrm{~m}$ by $100 \mathrm{~m}$ with a circle radius of $20000 \mathrm{~m}$.

\subsection{Survey for ranking}

The coastal zones of the Bohai Sea have multiple uses including aquaculture, tourism, harbor, mineral exploitation, salt industry and so on as shown in the Fig. 3. These sectors have different economic importance. Impact of oil pollution on these economic sectors is difficult to quantify. Hence, the pollution effect $(E)$ to these coastal uses was ranked by a designed questionnaire in a pilot survey. In the survey, ten scientists having background of oil pollution were selected from the Yantai Institute of Coastal Zone Research and were presented a questionnaire, in which effect were defined as 10 scales from 1 to 10 . Among the ten scales, 1 represents no effect at all and 10 represents a deadly severe effect. Moreover, the relevant contribution of pollution caused by ship or oil platform 


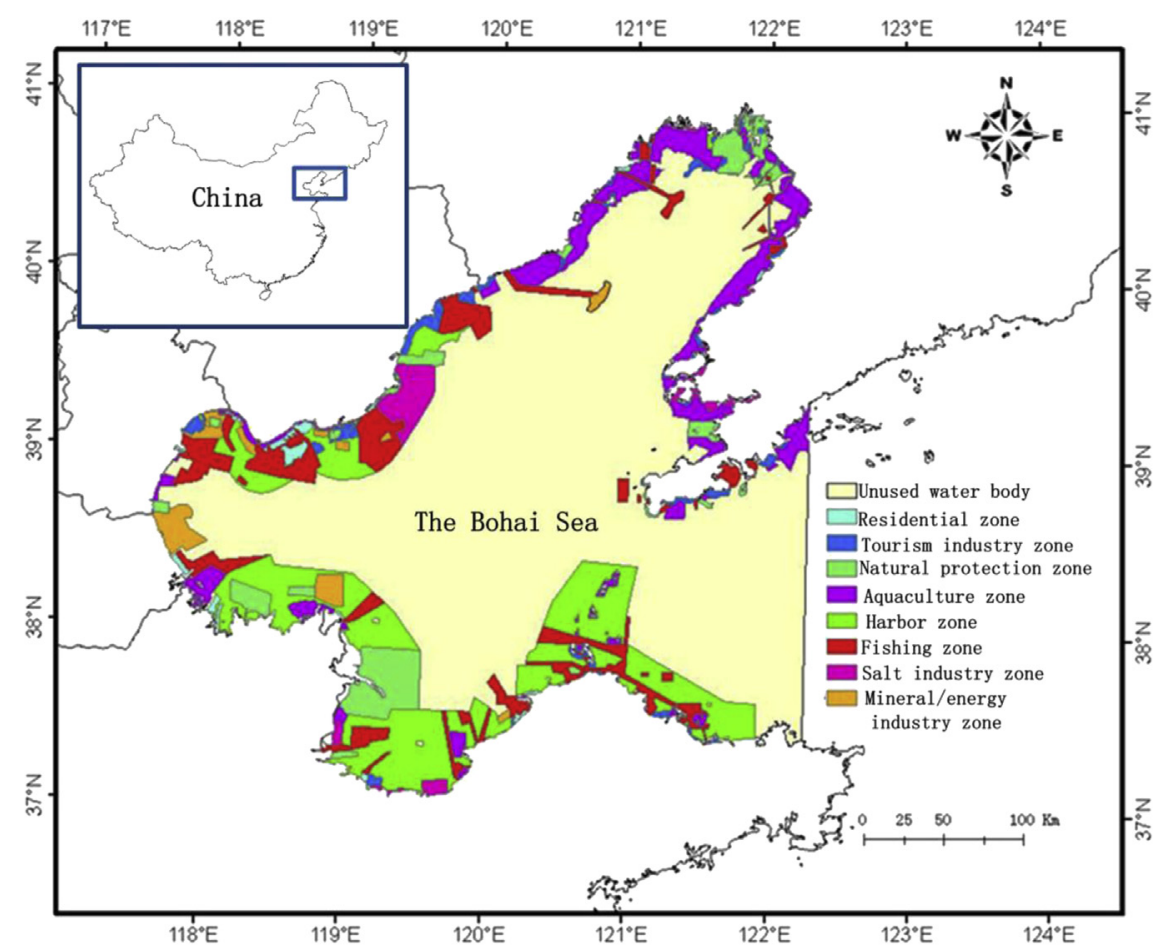

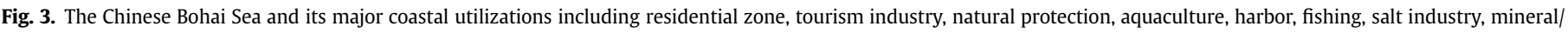
energy industry and other water body (as modified based on zonal functions from governmental planning).

to the coastal environment in the Bohai Sea (i.e., the modifier: $F_{\text {ship }}$ and $\left.F_{\text {oil }}\right)$ were weighted as well in the same survey. The inputs to these selected parameters were overviewed and were summarized in the following Table 2.

Table 2

An overview of all selected parameters and their values.

\begin{tabular}{|c|c|c|}
\hline Parameters & Values & Remarks \\
\hline$P_{\text {ship }}$ & $\begin{array}{l}0.00445 \text { for year } 2007 \\
0.00295 \text { for year } 2009 \\
0.0021 \text { for year } 2010\end{array}$ & $\begin{array}{l}\text { Probability of accidents related } \\
\text { to an individual ship }\end{array}$ \\
\hline$P_{\text {oil }}$ & 0.0000299 & $\begin{array}{l}\text { Probability of accidents related } \\
\text { to an individual oil platform }\end{array}$ \\
\hline$V_{\text {ship }}$ & 275.94 tons & $\begin{array}{l}\text { An average volume spilled per } \\
\text { ship accident }\end{array}$ \\
\hline$V_{\text {oil }}$ & 275.94 tons & $\begin{array}{l}\text { An average volume spilled per } \\
\text { oil platform accident }\end{array}$ \\
\hline$D_{\text {ship }}$ & $\begin{array}{l}\text { Spatially varied in the range of } \\
\text { [0 0.164] }\end{array}$ & Density of ship in the Bohai Sea \\
\hline$D_{\text {oil }}$ & $\begin{array}{l}\text { Spatially varied in the range of } \\
\text { [0 0.0032] }\end{array}$ & $\begin{array}{l}\text { Density of oil platforms in the } \\
\text { Bohai Sea }\end{array}$ \\
\hline$F_{\text {ship }}$ & 6.5 & $\begin{array}{l}\text { Modifier for ship accidents } \\
\text { (weighted within the range of } \\
{\left[\begin{array}{ll}1 & 10\end{array}\right] \text { in a pilot survey) }}\end{array}$ \\
\hline$F_{\text {oil }}$ & 8.45 & $\begin{array}{l}\text { Modifier for oil platform } \\
\text { accidents (weighted within a } \\
\text { range of }\left[\begin{array}{ll}1 & 10\end{array}\right] \text { in a pilot survey) }\end{array}$ \\
\hline E & $\begin{array}{l}4.45 \text { for unused water body } \\
3.85 \text { for harbor zone } \\
7.05 \text { for residential zone } \\
8.55 \text { for natural protection zone } \\
9.05 \text { for aquaculture zone } \\
8.55 \text { for fishing zone } \\
3.65 \text { for mineral/energy } \\
\text { industry zone } \\
8.55 \text { for tourism industry zone } \\
8.05 \text { for salt industry zone }\end{array}$ & $\begin{array}{l}\text { Mean value of oil pollution } \\
\text { effect to a multiple of coastal } \\
\text { zones (ranked/quantified } \\
\text { within a range of [ }\left[\begin{array}{ll}0 & 10\end{array}\right] \text { in a } \\
\text { pilot survey) }\end{array}$ \\
\hline
\end{tabular}

\section{Results and discussions}

The Bohai Sea is densely trafficked but shallow area connecting with the outer Huanghai Sea between China, North Korea and South Korea. Ships operating in the Bohai Sea mainly belong to six categories: cargo ships, tanker ships, container ships, passenger ships and military ships. Along the Bohai Sea coasts, there exist up to 21 ports. They are: the Zhuanhe port, the Pulandian port, the Dalian port, the Yingkou port, the Jinzhou port, the Huludao port, the Qinhuangdao port, the Tangshan port, the Tianjin port, the Huangye port, the Binzhou port, the Dongying port, the Weihai port, the Laizhou port, the Longkou port, the Changdao port, the Penglai port, the Yantai port, the Jinshan port, the Weihai port, the Chaoyang port. Therefore, the whole Bohai Sea nearly was covered densely by ship routes.

The difference of accidental probability linked with ship types was not discussed in details in the proposed paper, although ship type is an important factor involved in determining the occurrence of ship related oil accident. On the one hand, our focus in the proposed paper is not to model the relationship between accidental rate and the characteristics of ships including ship type, ship structure, ship age, available contingency resources in ships. On the other hand, overview of ship types and their routes being in the charge of the State of Ocean Administration (SOA). These information is confidential for the public.

Generally, ships are taken as moving targets. Satellite images reflect only their provisional locations as shown in Fig. 4 (b),(c),(d). There were 672, 1014 and 1428 ships in the investigation area for the year 2007, 2009 and 2010, respectively. Comparing Fig. 4 (b),(c),(d), there existed much more ships extracted in 2010, which indicated that transportation has became more and more extensive in the Bohai Sea recently. It is noted that these extractions of ships only represent a transient picture of navigation at a specified time period in the Bohai Sea. For an attempt to summarize 

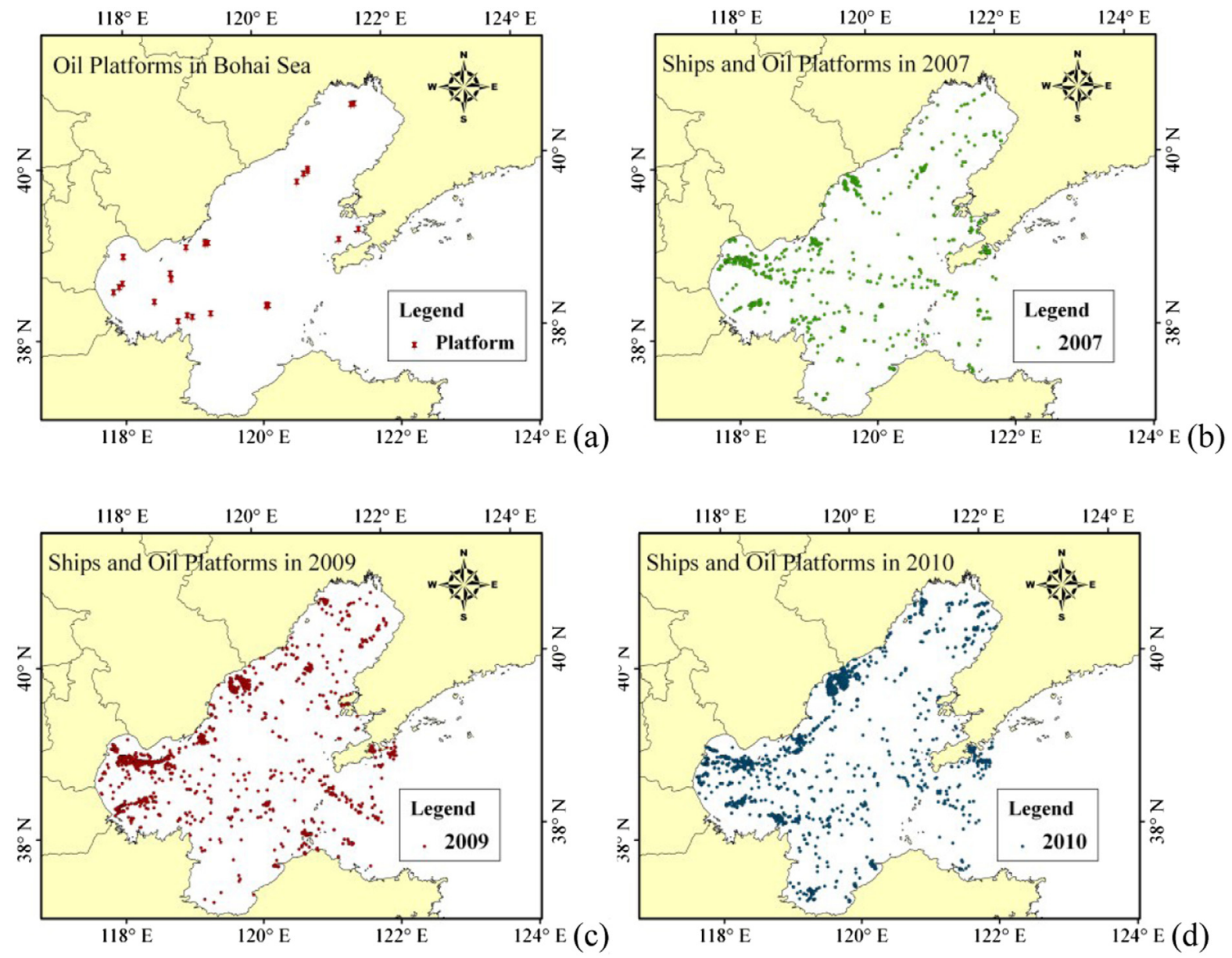

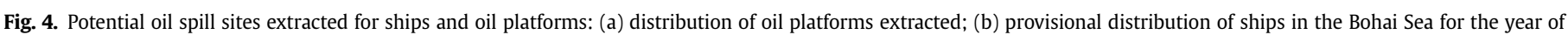
2007; (c) provisional distribution of ships in the Bohai Sea for the year of 2009; (d) provisional distribution of ships in the Bohai Sea for the year of 2010.

firstly the oil spill risk in the Chinese Bohai Sea, we took the transient pictures as granted to be analyzed further. For a comprehensive analysis in the future, more satellite images for four seasons should be presented.

Unlike ships, oil drilling platforms were fixable. Overlapping Fig. 4 (b),(c),(d) was able to target oil platforms. Targets of oil platforms were further validated with information from domestic literature (SOA, 2008). Fig. 4 (a) represented a distribution of oil drilling platforms located alongshore and offshore. 25 platforms in total were detected by analyzing all those selected satellite images. Actually, according to domestic literature there were 48 oil drilling platforms reported in the Bohai Sea. So the detection rate was only $52 \%$. This was partly because some oil drilling platforms were built after 2007. This can be improved by using more recent satellite data.

Fig. 5 provided a comprehensive image of oil spill risk in the Bohai Sea. As discussed in the previous section, oil spill risk was a product resulted from a variety of factors including type of accidents, spill probability, spill volume, pollution effect and so on. Based on the evaluation of oil spill risk, seven high risk zones were identified as shown in the Fig. 5. All these high risk zones were along coastal areas. This can be explained by a fact that economic value of coastal resources plays an important role in ranking pollution effect. Compared with platform related spill risk, ship related spills dominated in the Bohai Sea. Especially, Dalian harbor in the zone 1 has been established to be a deep-water port in 2013, which indicates its ship related spill risk will be increased significantly. It is important to note that the absolute value of the spill risk estimated was not a major concern, as the aim of the model was to compare the relative difference between coastal areas (Eide et al., 2007).

The locations of high risk zones determined were useful for a proper handle of removal of oil after spill. As these highlighted seven zones suggested that enough recovery equipments for oil spill combat should be presented near these high risk zones prespill. Recovery equipments such as boomers and skimmers needed for a quick response to oil spill is able to mitigate harm to coastal environment (Jung and Lee, 2013).

There was also uncertainty arising from the inputs data. For example, the spill risk assessment was subject to pollution effect. However, ranking for pollution effect was obtained through a questionnaire in a pilot survey, in which a questionnaire was presented to research scientists working at the coastal institute. It should be addressed that such a pilot survey involving a small number of respondents could lead to uncertain and biased result (Liu and Wirtz, 2010). For accurate quantification of pollution effect in the next work, it is suggested that exact market valuation of coastal areas in money terms to be applied. For instance, the value of aquaculture zone could be valued by the yearly economic income of the mari-culture sector.

The results obtained with the proposed model could be used with care for decision support, not a decision making (Eide et al., 2007). All decisions must be made by a qualified human, not a computer, and all decisions should be made based on all available information (Skinner, 2001) and no rely on any one model alone. 


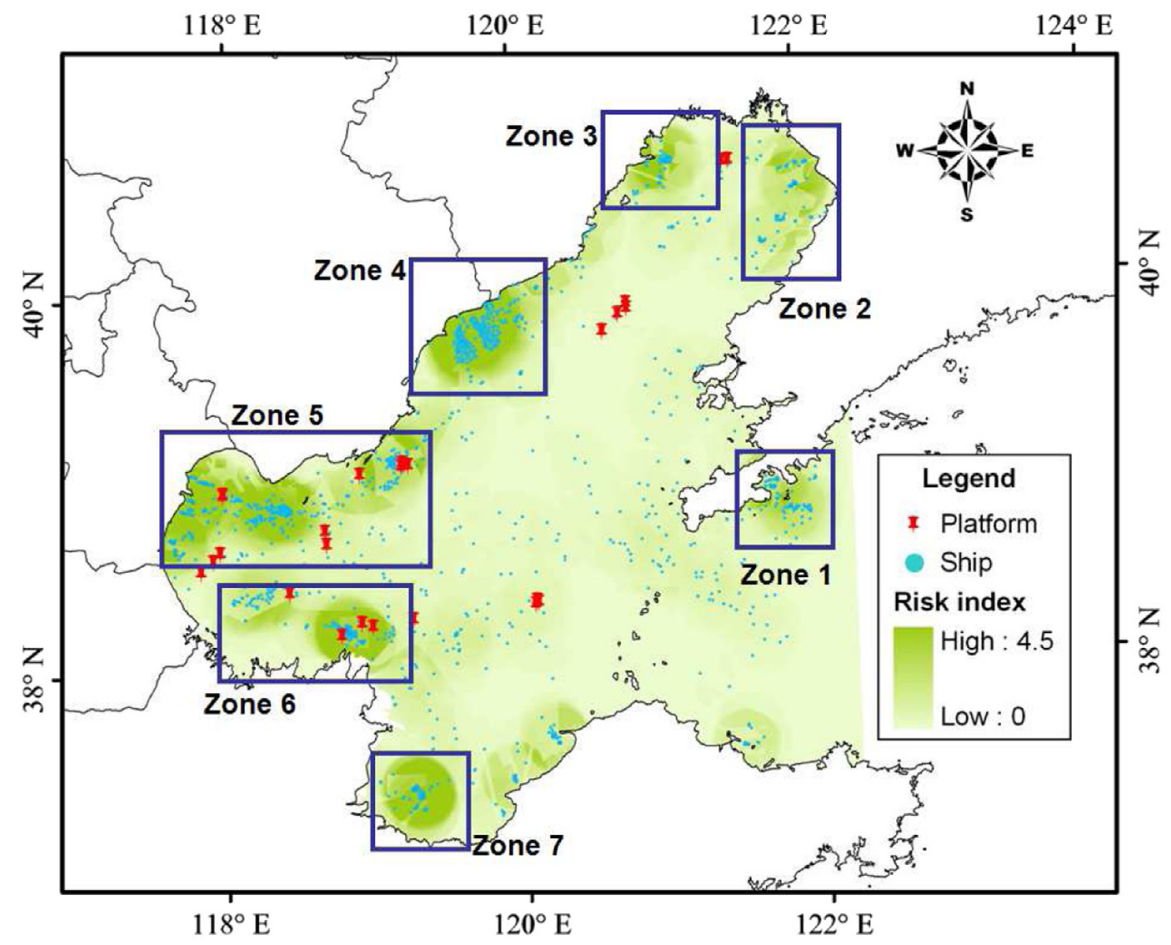

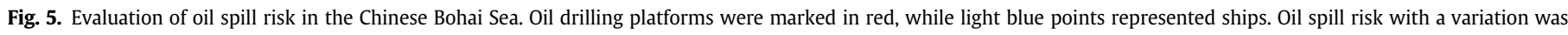
marked in green (for reference see the legend right). High risk zones were marked in a blue rectangular.

\section{Conclusions}

In this study, we made an attempt to assess oil spill risk for both the ships and the oil drilling platforms related accidents at the Bohai Sea, China. Multiple sources of data including remote sensing data, historical spill records that occurred between 1973 and 2002 for the Bohai Sea were involved in this work. First of all, potential spill sites such as oil drilling platforms and ships were determined by the decision algorithm. Spill risk as a product of accidental probability and pollution effect was then calculated spatially. Finally, the seven high risk zones in the Bohai Sea were identified. All high risk zones were distributed along the coast, which means that coastal economic use plays an important role in ranking of pollution effect.

Additionally, ship accidents still dominate the risk in the Bohai Sea. According to the results, preparedness for combat of oil spill should be suggested within the seven high risk zones. For a proper handle of removal of oil on waters, enough recovery equipments needed should be prepared in those high risk zones pre-spill.

\section{Acknowledgments}

This work was jointly supported by Yantai Science and Technology Bureau (No.2013ZH081), the National Natural Science Foundation of China (No. 41371483), the open fund of Key Laboratory of Marine Spill Oil Identification and Damage Assessment Technology, SOA (No.201208). Authors would like to thank all research scientists and students involved in the pilot survey, and three anonymous reviewers for their suggestions and improvements on this manuscript.

\section{Appendix A. Supplementary data}

Supplementary data related to this article can be found at http:// dx.doi.org/10.1016/j.ocecoaman.2014.08.016.

\section{References}

Castanedo, S., Juanes, J.A., Medina, R., Puente, A., Fernandez, F., Olabarrieta, M. Pombo, C., 2009. Oil spill vulnerability assessment integrating physical, biological and socio-economical aspects: application to the Cantabrian coast (Bay of Biscay, Spain). J. Environ. Manag. 91, 149-159.

China Daily, 2013. Oil Spill from Qingdao Blast Kills Sea Life. http://www.chinadaily com.cn/photo/2013-12/23/content 17191685.htm.

COPC, 2012. http://www.conocophillips.com.cn/EN/Response/Pages/default.aspx.

Crichton, D., 1999. The risk Triangle. In: Ingleton, J. (Ed.), Natural Disaster Management. Tudor Rose, London, pp. 102-103.

Det Norske Veritas ( DNV ), 2011. Final Report on the Assessment of the Risk of Pollution from Marine Oil Spills in Australian Ports and Waters. Australian Maritime Safety Authority, pp. 1-3. http://www.amsa.gov.au/marine_ environment_protection/national_plan/Reports-Fact_Sheets-Brochures/ DNVReport.asp.

Eide, M.S., Endresen, Ø., Brett, P.,O., Ervik, J.L., Røang, K., 2007. Prevention of oil spill from shipping by modelling of dynamic risk. Mar. Pollut. Bull. 54, 1619-1633.

El-Fadel, M., Abdallah, R., Rachid, G., 2012. A modeling approach toward oil spil management along the Eastern Mediterranean. J. Environ. Manag. 113, 93-102.

Etkin, D.S., 2004. Modeling Oil Spill Response and Damage Costs. EPA, USA GOV p. 40.

French-McCay, D., Etkin, D.S., Beegle-Krause, C.J., Rowe, J., Rodriguez, W., 2009. Oil spill risk assessment - relative impact indices by oil type and location. In: Proceedings of the 32nd AMOP Technical Seminar on Environmental Contamination and Response. Emergencies Science Division, Environment Canada, Ottawa, Canada, pp. 655-681.

Gundlach, E.R., Hayes, M.O., 1978. Vulnerability of coastal environments to oil spill impacts. Mar. Technol. Soc. J. 12, 18-27.

Hanna, R.G.M., 1995. An approach to evaluate the application of the vulnerability index for oil spills in tropical Red Sea environments. Spill Sci. Technol. Bull. 2, $171-186$.

Huludao Evening News, 2010, http://www.In.chinanews.com/html/2010-12-27/ 182827.html.

Lamine, S., Xiong, D., 2013. Guinean environmental impact potential risks assessment of oil spills simulation. Ocean. Eng. 66, 44-57.

Lao, H., 2003. Statistical records of oil spills larger than 50 tons in the Chinese Sea for the last 29 years. Environ. Prot. Transp. 24 (6), 46.

Lee, M.J., Jung-Yeul Jung, J.Y., 2013. Risk assessment and national measure plan for oil and HNS spill accidents near Korea. Mar. Pollut. Bull. 73, 339-344.

Liu, X., Wirtz, K., 2010. Managing coastal area resources by stated choice experiments. Estuarine. Coast. Shelf Sci. 86, 512-517.

Meng, R., Xing, Q., 2013. Detection of offshore ship and well platform based on optical remote sensing images. J. Comput. Appl. 33, 708-711.

Nansingh, P., Jurawan, S., 1999. Environmental sensitivity of a tropical coastline (Trinidad, West Indies) to oil spills. Spill Sci. Technol. Bull. 5, 161-172. 
Petersen, J., Michel, J., Zengel, S., White, M., Lord, C., Plank, C., 2002. Environmenta Sensitivity Index Guidelines Version 3.0. U.S. National Oceanic and Atmospheric Administration, Seattle, p. 89. Technical Memorandum NOS OR\&R 11.

Roeleven, D., Kok, M., Stipdonk, H.L., de Vires, W.A., 1995. Inland waterway transport: modelling the probability of accidents. Saf. Sci. 19, 191-202.

Romero, A.F., Abessa, D.M.S., Fontes, R.F.C., Silva, G.H., 2013. Integrated assessment for establishing an oil environmental vulnerability map: case study for the Santos Basin region, Brazil. Mar. Pollut. Bull. 74, 156-164.

Santos, C.F., Michel, J., Neves, M., Janeiro, J., Andrade, F., Orbach, M., 2013. Marine spatial planning and oil spill risk analysis: finding common grounds. Mar Pollut. Bull. 74, 73-81.

Skinner, D.C., 2001. Introduction to Decision Analysis, Second ed. Probabilistic Publishing, USA, ISBN 0-9647938-3-0.

Smith, R.A., Slack, J.R., Wyant, T., Lanfear, K.J., 1982. The Oil Spill Risk Analysis Model of the US Geological Survey. Geological Survey Professional Paper 1227. US Geological Survey, Reston,VA, USA, p. 36.
SOA, 2008. Environmental Quality Bulletin for the Bohai Sea in 2008. http://www. soa.gov.cn/zwgk/hygb/zghyhjzlgb/hqhjzlgb/2008nbh/201212/t20121213_ 22762.html.

Vethamony, P., Sudheesh, K., Babu, M.T., Jayakumar, S., Manimurali, R., Saran, A.K., Sharma, L.H., Rajan, B., Srivastava, M., 2007. Trajectory of an oil spill off Goa, eastern Arabian Sea: field observations and simulations. Environ. Pollut. 148, 438-444.

Wei, H., Hainbucher, D., Pohlmann, T., Feng, S., Suendermann, J., 2004. Tidalinduced Lagrangian and Eulerian mean circulation in the Bohai Sea. J. Mar. Syst. 44, 141-151.

Wu, G., De Leeuw, J., Skidmore, A.K., Liu, Y., Prins, H.H.H., 2009. Performance of Landsat TM in ship detection in turbid waters. Int. J. Appl. Earth Observation Geoinformation 11, 54-61.

XINHUA Press, 2010. http://green.sina.com.cn/news/roll/2010-07-20/10532071 7428.shtml. 